\title{
FAULT IDENTIFICATION IN TRANSFORMER WINDING
}

\author{
S.Joshibha Ponmalar ${ }^{1}$, S.Kavitha ${ }^{2}$ \\ ${ }^{1,2}$ Department of Electrical and Electronics Engineering, Saveetha Engineering College, (Anna University), Chennai
}

\begin{abstract}
Transformer fault detection during impulse tests has always been an important topic in power engineering. Transformers connected to overhead lines are often prone to lightning strikes and resulting winding damage. For assessment of their insulation strength against such impulse stresses they are usually subjected to lightning impulse tests after assembly. In the case of a fault inside the winding, the shape of the winding current changes as compared to that of a healthy winding. The pattern of the fault current depends on the type of fault and its location along the length of the winding. This paper investigates Conventional procedures of fault diagnosis involved visual examination of the oscillographic records in time-domain and also applying the Fast Fourier Transform (FFT) algorithm to analyze the transformer 'fingerprint' in the frequency-domain. Actually, this method is straight forward technique for interpretation of minor impulse faults in transformers. Also Simulation results obtained for a range of distribution transformer digital models are presented to illustrate the ability of this approach to classify insulation failures during impulse testing. The proposed method has been applied for impulse fault analysis of a analog model of a $12 \mathrm{kVA}$ single phase transformer.
\end{abstract}

Keywords: transformer; Impulse test; Fault; FFT

\section{INTRODUCTION}

High voltage power transformers are subjected to full and chopped impulse voltages of specified values in accordance with the standard requirement to as certain the insulation integrity. Partial or complete failure of transformer is reflected in the change of voltage or neutral current transient characteristics. Accurate diagnosis of faults in transformers can significantly enhance the safety, reliability, and economics of power systems. In the case of a fault, it has been established that the pattern of the fault currents contain a typical signature of the nature and location of the fault for a given winding. The transfer function technique has proved quite effective in diagnosing the fault in the transformer.

1. S.Joshibha Ponmalar M.E. (High voltage) is an Assistant Professor in the department of Electrical and Electonics Engineering, Saveetha Engineering College, Chennai, India.

E-mail: lettertojoshi@yahoo.com

2. S.Kavitha M.E. (Power Electronics and Drives) is an Assistant Professor with the department of Electrical Engineering and Electonics Engineering, Saveetha Engineering College, Chennai, India.

Distribution transformers connected to overhead lines have high probability of lightning impulse attacks. Especially since the need for employing lightning arresters are often overlooked for smaller range distribution transformers. Impulse testing of transformers after assembly is now an accepted procedure for the assessment of their winding insulation strength to impulse over voltages. Impulse voltages of the standard specifications $[1,2]$ are generated in the laboratory and applied to the transformers. Fault may occur in the winding during such tests due to improper or inadequate insulation. In the case of such a fault, it is essential to detect the fault and its location in the winding for repair work. Finding the fault location manually involves taking the winding out of the tank - and this involves a lengthy procedure. For many years now, the applied impulse voltage and the resulting current waveforms were analyzed manually by studying oscillographic records [2-6]. Any deviation in the current wave shape corresponding to the reduced impulse voltage and the subsequent full impulse voltage was attributed to a winding fault. Such manual interpretation of the waveform patterns for fault identification and classification was invariably dependent on the knowledge and experience of the experts performing the analysis. With the advent of digital recorders and analyzers, there has been an increasing trend to use the frequency domain analysis, particularly the transfer function approach [7-9] for fault classification. In this case, once again, fault diagnosis was based upon identification of any deviation between the transfer functions corresponding to reduced and subsequent full impulse voltage tests.

In general, a diagnostic procedure depends on the understanding of the physical behavior of the transformer winding under consideration. In this phase, the knowledge of well-tested models able to simulate the transformer winding in different fault conditions is important to obtain the patterns characterizing the faults. High frequency modeling of a range of distribution transformers is incorporated into the simulation using the PSPICE package. The simulation also involves the modeling of the faults between any disc and the earth and between any two discs of the transformer windings. In order to carry out analysis, faults are also created in turns of the tapping 
winding of a $12 \mathrm{kVA}, 220 / 75000 \mathrm{~V}$ single phase Transformer at different locations. Neutral currents are recorded by applying low voltage impulse through impulse Generator. Contribution of each frequency in time domain signal is calculated. The proposed method can be used for isolating the contribution due to any frequency change in the waveform.

Maleswki et a1 [10] reported earlier that an impulse response analysis could identify faults from resonant frequency shift and resonant pole damping. However, all of the previous approaches fell short of explaining the changes in transfer function in relation to a mathematical model of a transformer in locating faults along the winding. Future research should concentrate on these issues as well. In this paper, a comprehensive analog model is proposed which can model leakage faults and partial discharges as well as winding displacement, short circuit etc. These results contributes to enrich the ability of the transfer function approach as an excellent tool for condition monitoring by locating faults in power transformers.

\section{TRANSFORMER MODEL}

\subsection{Simulation Model}

Several authors $[11,12]$ in the past have developed analog model of a transformer capable of studying impulse voltage distribution and electromagnetic transients. In all the models, the discs winding of the HV sides of the transformers have been represented by a network with lumped parameters as shown in Fig. 1. These parameters include self-inductance, mutual inductance, series capacitance, ground capacitance and the winding resistance. The parameter 'ground capacitance' consists of several components including (i) capacitance between impulsed HV winding and grounded LV winding on the same limb, (ii) capacitance between the impulsed HV winding on side limb and the grounded transformer tank, (iii) Capacitance between impulsed HV winding on one limb and non-impulsed HV winding on another side limb. On the other hand, the parameter 'series capacitance' is composed of (i) inter-turn capacitance and (ii) inter-disc capacitance.

Table: 1 Transformer design data

\begin{tabular}{|c|c|c|}
\hline $\mathrm{P}$ & 100 & $\mathbf{3 0 0}$ \\
\hline $\mathrm{V}$ & $6.6 / 0.44$ & $\mathbf{6 . 6 / 0 . 4 4}$ \\
\hline $\mathrm{D}$ & 12 & $\mathbf{1 4}$ \\
\hline $\mathrm{OD}$ & 265 & $\mathbf{3 3 1}$ \\
\hline $\mathrm{ID}$ & 220 & $\mathbf{3 8 1}$ \\
\hline $\mathrm{T}$ & 1152 & $\mathbf{1 1 2 0}$ \\
\hline $\mathrm{L}$ & 78 & $\mathbf{9 5}$ \\
\hline $\mathrm{C}_{\mathrm{g}}$ & 0.6 & $\mathbf{0 . 8}$ \\
\hline $\mathrm{C}_{\mathrm{s}}$ & 2.6 & $\mathbf{1 . 9}$ \\
\hline $\mathrm{R}$ & 2.7 & $\mathbf{0 . 4 7}$ \\
\hline
\end{tabular}

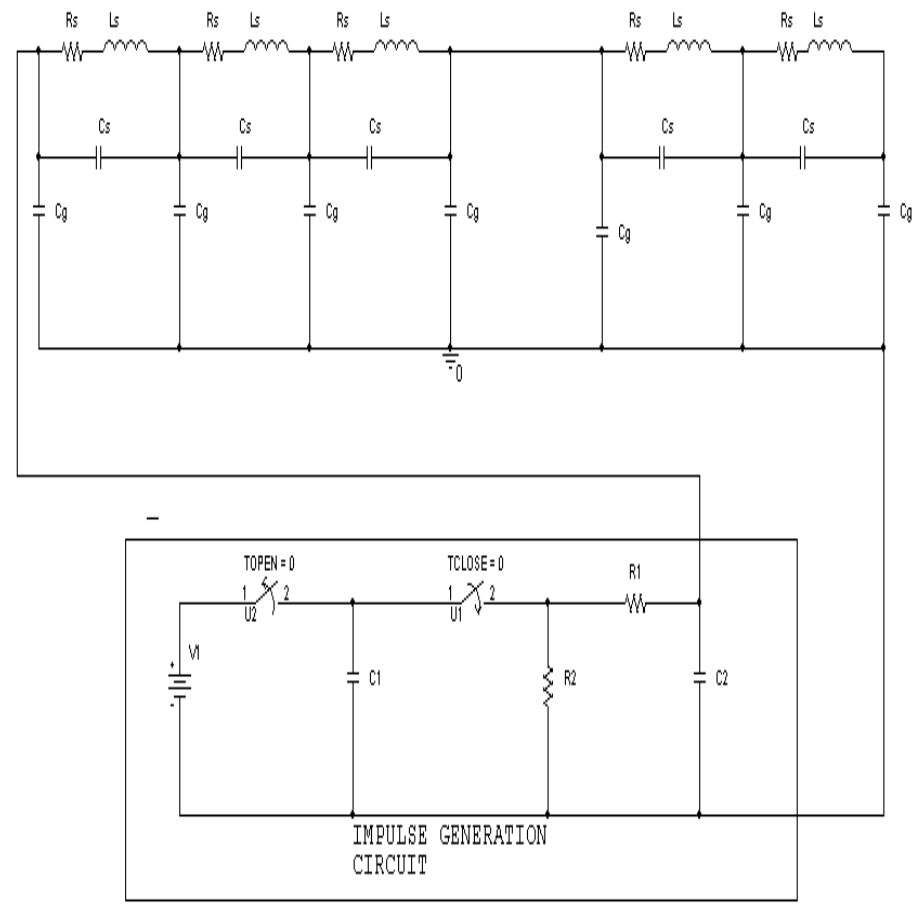

Figure1. Equivalent circuit of a single transformer winding at high frequencies

\subsection{Types of Fault Simulated}

Insulation failures may result in two classes of winding faults in a transformer during impulse tests - namely series and shunt faults. Series fault implies insulation failure between the discs or between the turns, while shunt fault represents insulation failure between the winding and earthed components like tank, core, etc. A series fault has been simulated with a low resistance discharge path between two consecutive discs. A shunt fault has been simulated by a similar discharge path between a particular disc at the top/middle/bottom end of the winding, as the case may be, and the grounded tank. The winding current records corresponding to the reduced voltage level (calibrating wave). All the current waves considered for analysis have been converted into a per unit scale to effectively take into account the possible variations in current wave due to applied voltage wave magnitude variations. Each fault has been made to involve $5-10 \%$ of the entire winding length. To investigate the sensitivity of the proposed method, shunt faults were simulated at three different locations along the length of the winding - namely line-end, middle and earth-end of the winding. Series faults simulated at different locations in the winding, however, did not show appreciable variations in the corresponding current waves. This may be due to the limited number of discs present in the range of transformers under study. 
Table 2 Types of different faults simulated

\begin{tabular}{|c|c|}
\hline Acronyms & Faults \\
\hline NF & No-fault \\
\hline SEE & Series fault at end \\
\hline SES & Series fault at mid-winding \\
\hline SEM & Shunt fault at end \\
\hline SHE & Shunt fault at mid-winding \\
\hline SHM & \\
\hline
\end{tabular}

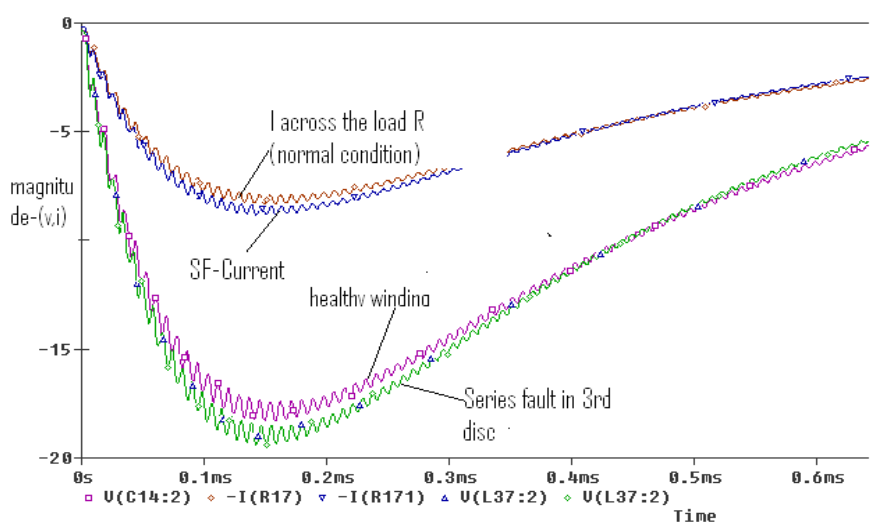

Fig. 2 Time-domain plot for simulated series fault at start sectionin $300 \mathrm{kVA}$ transformer

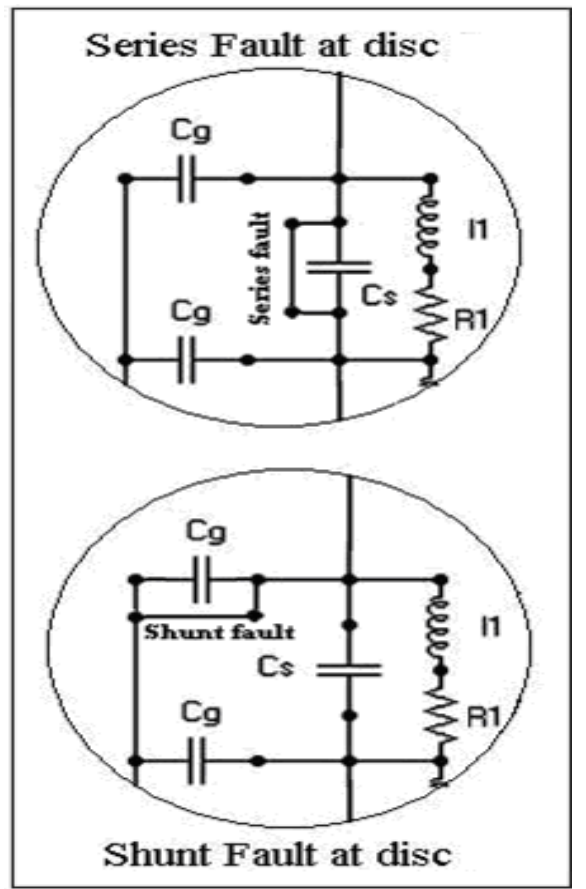

Fig3. Sample fault of the simulation model.

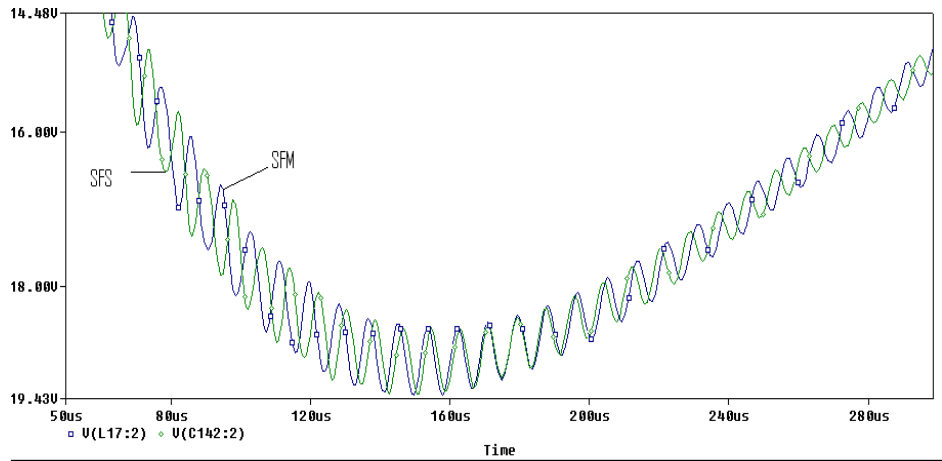

Fig 4. Time-domain plot for simulated series fault at start and middle section in $300 \mathrm{kVA}$ transformer

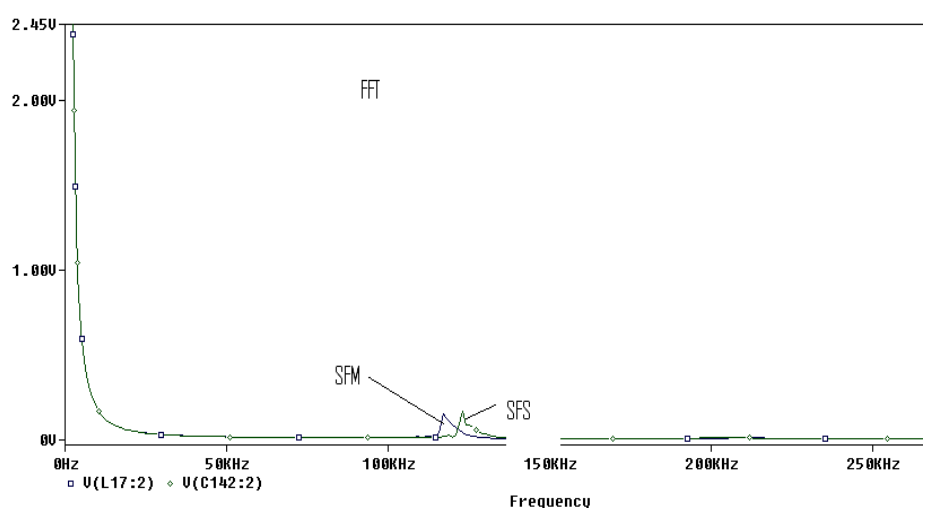

Fig 5. FFT plot for simulated series fault at start and middle section in $300 \mathrm{kVA}$ transformer

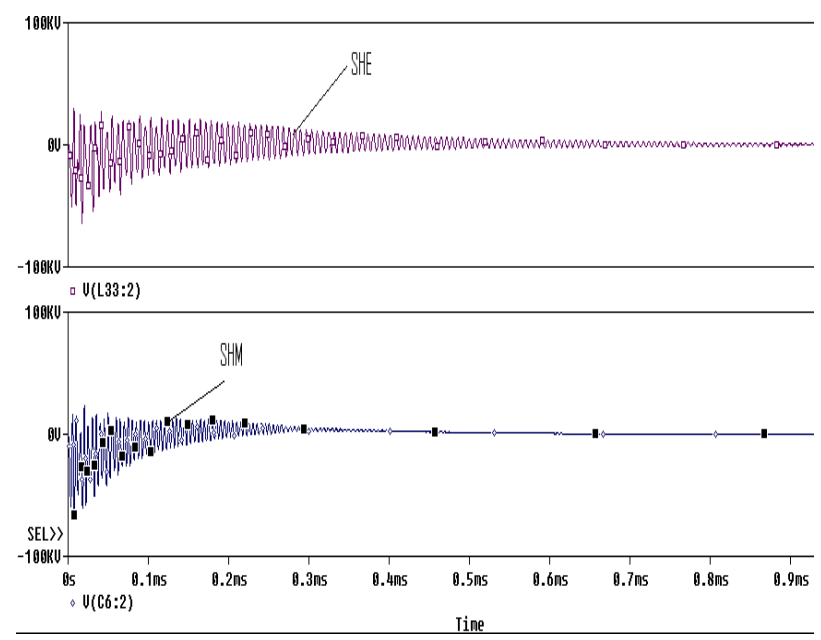

Fig. 6. Time-domain plot for simulated shunt fault at lineendsection andTime-domain plot for shunt fault at mid-winding section of a transformer

\subsection{Analog model}

An analog model used has a specification 12-kVA, 220/750001V, single-phase, 50-Hz, transformer. The high- 
voltage (HV) winding of the transformer is considered to be impulse tested as per IEC publication 76-3, 1980 [1]. The impulse data acquisition setup incorporating the analog model is shown in Fig. 7.The impulse voltage and winding current waveforms reduced impulse waves were recorded by a Tektronix model-714L, 500-MHz, 4 channel DSO 500MSamples/s digital storage oscilloscope. The waveforms were then transferred to the PC through an RS-232 interface. The "Wave Star" software was used in the PC for acquiring the data from the oscilloscope. The waveforms were subsequently transferred to the data storage of the system.

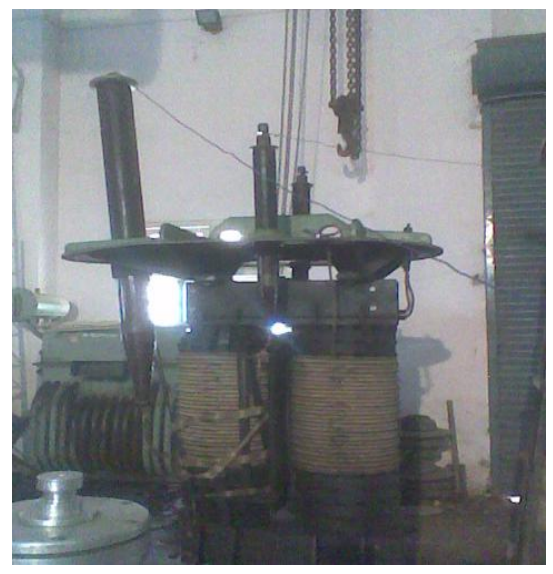

Fig7. Experimental analysis of impulse faults in 12kVA transformer

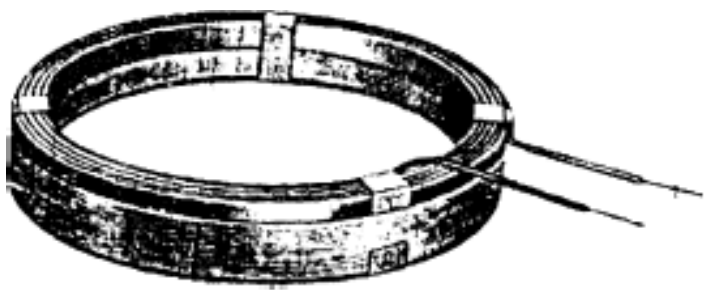

Fig8. Sample disc coil of the analog model

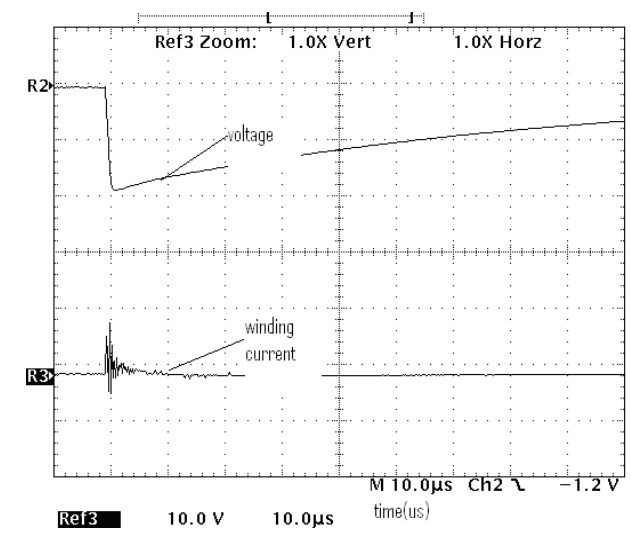

Fig9. Spark over during LI under normal healthy condition transformer

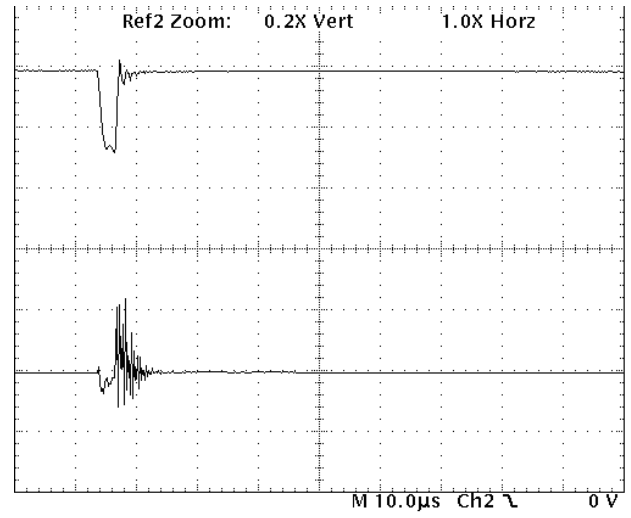

Fig10. Spark over during LI under series fault created at starting end

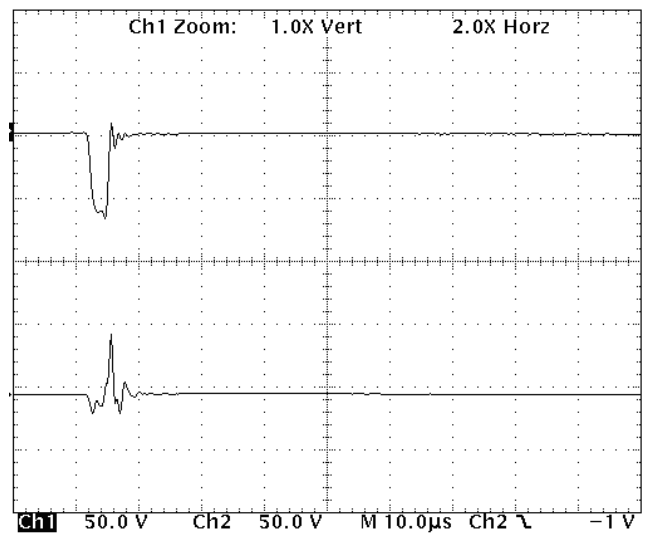

Fig11. Spark over during LI under series fault created at ending

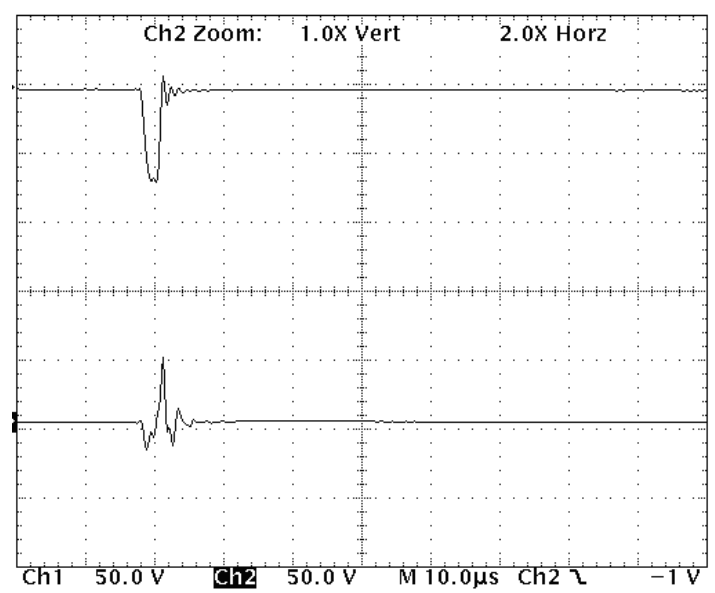

Fig12. Spark over during LI under multiple faults 


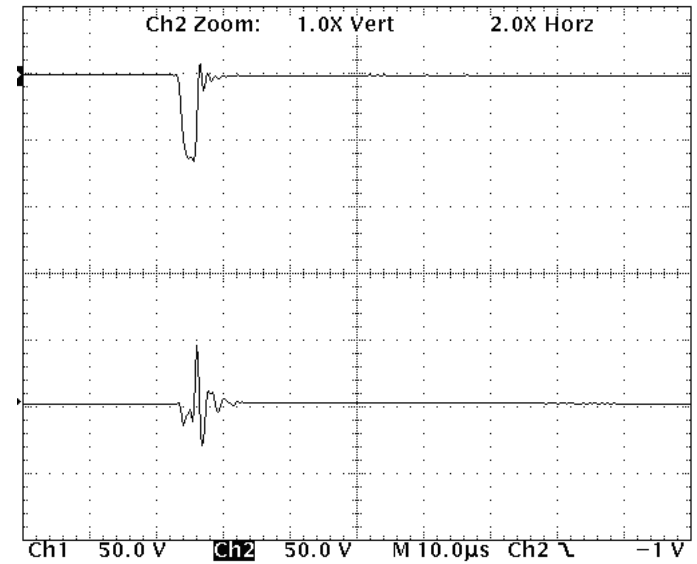

Fig13. Spark over during LI under shunt fault

\section{FAULT CLASSIFICATION}

\section{Frequency-domain analysis}

The rule-base corresponding to frequency-domain analysis involves comparison between the TFs calculated for the calibrating impulse wave and the impulse wave at BIL. The TF is calculated from the Fast Fourier Transform (FFT) of the current and voltage records as:

$\mathrm{TF}=\underline{\mathrm{FFT}}(\mathrm{i})$

FFT (v)

The detection of the type of fault and its location determination is then based upon the diagnostic indexes calculated from certain parameters such as deviation in the resonant poles, their magnitudes as well as frequencies between the two TFs at calibrating level and BIL, respectively. A turn-to-turn fault will introduce new poles at the high frequency part of the TF plot or in other words will shift the original poles towards a higher frequency as shown in Fig. 14 [19]. According to [15,17] shunt fault at line-end section is characterized by a huge increase in the magnitude of fault current and large attenuation of the oscillations*/ in most cases the corresponding resonant poles are Completely shaved off. Shunt fault at mid winding section is characterized by an increase in the oscillation frequency [14, $15,16,17]$, which is depicted by a large shift of the poles of the TF towards higher frequency. Shunt fault at earth end section, however, only shifts the oscillation peaks without changing the frequency or magnitude of oscillation much. As described by Vajana et al. [18], the FFT curves for both the current and voltage waves need to be calculated up to $200 \mathrm{kHz}$ with at least 1000 sampling points. However, the first few dominant poles of the TF being confined within a span of $100 \mathrm{k}$ calculated up to a frequency of $100 \mathrm{kHz}$ it is sufficient to carry out fault diagnosis based on TFs calculated up to a frequency of $100 \mathrm{kHz}$.

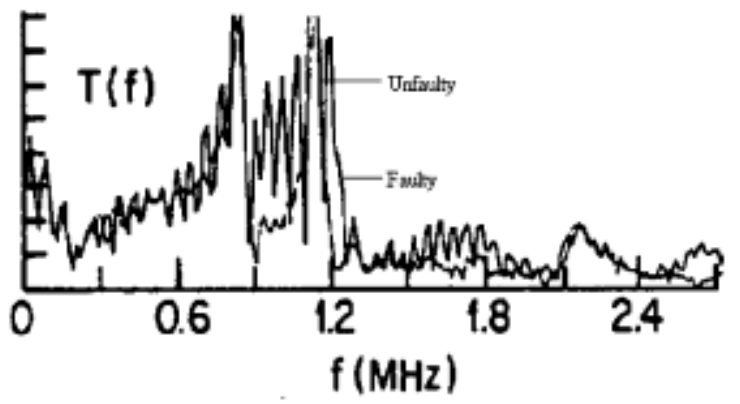

Fig14. Frequency-domain plot (TF) for coil-to-coil series fault

\section{CONCLUSIONS}

This paper reports an method to identify and find the location of different types of impulse faults in transformers using time and frequency domain analysis. The incorporation of both the time and frequency domain analyses ensures high reliability in the fault diagnosis process. In the current work, PSPICE based high frequency digital model studies for a range of transformers, 100 and $300 \mathrm{kVA}$ have been used in conjunction with published literatures. Winding currents in transformers vary to different extent depending upon the type of impulse faults. Using the proposed method we can identify the fault s of the transformer during impulse test.

\section{REFERENCES}

[1] Power Transformer - Insulation Levels and Dielectric Tests, IEC Publication 76-3, 1980.

[2] Guide to the Lightning and Switching Impulse Testing of Power Transformers and Reactors, IEC Standard Publication 722, 1982.

[3] F. Beldi, The impulse testing of transformers, Brown Boveri Rev. 37 (1950) 179-193.

[4]. J.H. Hagenguth, J.R. Meador, Impulse testing of power transformers, AIEE Trans. 71 (1952) 697-704.

[5] C. Aicher, Experience with transformer impulse failure detection methods, AIEE Trans. 67 (1948) 1621-1631.

[6]. G.B. Harper, Detection and Diagnosis of Deterioration and Faults in Power Transformers, CIGRE, Paper 12.01, 1967, pp. $19-25$.

[7] R. Malewski, B. Poulin, Impulse testing of power transformers using the transfer function method, IEEE Trans. Power Delivery 3 (1988) 476-490.

[8]. J. Bak-Jensen, B. Bak-Jensen, S.D. Mikkelsen, Detection of faults and ageing phenomena in transformers by transfer functions, IEEE Trans. Power Delivery 10 (1995) 308-314.

[9] R. Vajana, K. Udayakumar, Fault location in power transformers during impulse tests, in: Proceedings of the 2000 IEEE PES Winter Meeting, Singapore. Paper No. 150106 [10]. R. Malewski and 13. Poulin,"Impulse "Testing of Power Transformer Using the Transfer Function Method", IEEE 'Trans. on Power Delivery, Vol.3, No. 2, April 1988, pp. 476489. 
[11]. Q. Su and 1I.E. Janies." Analysis of Partial Discharge Pulse Distribution Along Transformer windings Using Digital Filtering Techniques", IEE Proc. PartC, Vol. 139, No. 5: 1992, pp. $402,-410$.

[12]. A. Miki, T. Hosoya, and IC. Okuyanla,"A Calculation Method for Impulse Voltage Distribution acid Transferred Voltage in Transformer Windings", IEEE Trans. PAS, Vol. PAS-97, No. 3, 1978, pp 930-939_/157

[13]. G.C. Dewsnap, E.G. Williams, Investigation of fault detection methods for the impulse testing of transformers, J. Inst. Eng. Australia 29 (1957) 311_/319.

[14] D.L. Buttrick, W.B. Harrington, Impulse testing*/methods of fault detection and location, Proceedings of the IEE Conference 149_/157, Diagnostic Testing of High Voltage Power Apparatus in Service, Publication no. 94, 1973, (Part 1) pp. 228_/237, (Part 2) pp. 79_/90.

[15] C.K. Roy, J.R. Biswas, Studies on impulse behavior of a transformer winding with simulated faults by analogue modeling, IEE Proc.-C 141 (1994) 401_/412.

[16] P. Purkait, S. Chakravorti, An expert system for fault diagnosis in transformers during impulse tests, Proceedings of the 2000 IEEE PES Winter Meeting, paper no. 15_01_03.

[17] P. Purkait, S. Chakravorti, Time and frequency domain analyses based expert system for impulse fault diagnosis in transformers, IEEE Trans. Dielectrics Electrical Insulation 9 (2002) 433_/445

[18] R. Vajana, K. Udayakumar, A new paradigm for impulse testing of power transformers, in Proc. 2000 IEEE PES Winter Meeting, paper no. 15_01_08. 